\title{
Virtual Interviews for Students Interacting Online for Psychiatry (VISIOn): a novel resource for learning clinical interview skills
}

Academic psychiatry departments have two principle roles within undergraduate medical education. The first is to increase knowledge about psychological and psychiatric disorders and their treatments. The second is to help students develop the clinical skills to sensitively, effectively and accurately interview patients with psychological problems (General Medical Council, 1993) and to assess the mental states of patients.

Traditionally, students are expected to interview many patients with acute and severe psychiatric disorders with, in many instances, only the benefit of some introductory lectures or tutorials. Students at Trinity College, Dublin have described this as an anxiety-provoking experience that continues for varying periods of time, depending on the student, before they feel comfortable conducting such patient interviews. Because clinical psychiatry is moving increasingly towards providing care in community settings there are fewer in-patient beds in teaching hospitals (Department of Health and Children, 2003); subsequently the students are less likely to be exposed to a sufficient number and range of patients. With patients also increasingly reluctant to be interviewed by multiple students, there are decreased learning opportunities in what is a core skill for all future doctors.

Research shows that psychiatric interview skills are traditionally best developed in small groups and with the use of video material (Maguire et al, 1986), although students may also find this teaching experience difficult (Nilsen \& Baerheim, 2005). The creation of interactive tools using videos and other electronic materials has been advocated as the logical progression in teaching clinical skills in psychiatry (Vassilas \& Ho, 2000). In recent years, role-playing by students and actors used as 'simulated patients' has become an established means of teaching communications skills at both undergraduate and postgraduate levels (Barrows, 1993). Simulated patients are now commonplace in health sciences education (Association of American Medical Colleges, 1999), but are expensive. Each tutorial with an actor requires a doctor to be present as tutor, an actor as patient, and considerable administrative input to ensure student, actor and tutor are brought together at the same time.

\section{Initial survey}

As a prelude to possible development of new teaching methods for clinical skills, we conducted a survey of a group of 34 medical students during their 2-month psychiatry placements. Ethical approval for the study was obtained from the Trinity College Dublin Faculty of Health Science Ethics Committee. Students were asked to rate what they found useful for learning interview skills in psychiatry and the following responses were obtained:

- tutorials from doctors (71\%)

- observing interviews by doctors/other professionals (78\%)

- conducting interviews themselves (100\%)

- video interviews of themselves/others $(80 \%)$

- books (72\%)

- web-based support (20\%).

In addition, we received qualitative comments, some of which are listed in Box 1. As a result of these responses we decided that existing methods were either too labour intensive and expensive, or failed to provide a critical interactive experience. We obtained grant funding to create an interactive video interview simulator that would orientate students quickly to the process of conducting interviews with patients. The aim was to enable students to be more prepared when they start to see patients in psychiatric wards. We considered that this would be better for students and patients and a more efficient use of the finite resources of student time and of psychiatric patients available and willing to be interviewed.

\section{What is VISIOn?}

To address this situation, an online interactive e-learning simulator called 'Virtual Interviews for Students Interacting Online for Psychiatry (VISIOn)' was developed. This allows students to choose an interview path through a psychiatric disorder. Along this path they view video clips of an actress portraying a patient with depression responding to the questions chosen by the student. Initially, the simulator shows the patient being greeted by the interviewer (the student). The patient responds. Then, the simulator allows the interviewer to choose their subsequent questions from a list based on their position on the interview path. Once the student chooses a question, they are presented with a video answer from the patient. As soon as the video clip is completed, the student chooses from a range of further questions and so on as the student progresses along their interview path. After asking a question the simulator provides feedback to the interviewer as to which type of question they have chosen (open question, closed question, clarifying statement, etc). Each patient's video response is also summarised in clinical terms. 
Box 1. Qualitative comments about learning interviewing techniques in psychiatry

- 'Not enough opportunities for practice'

- 'There was not a lot of opportunity to observe the consultant or other doctors interviewing patients'

- 'A big change from previous general surgery/medicine where questioning tends to be so specific/solid. Psychiatry is generally a bit more of a grey area. Signs and symptoms are often not so solid and their comprehension and interpretation requires a little more of an open mind'

- 'Easy to learn from a text book but much harder when you do it in person

- 'Most useful learning method was being allowed to interview patients alone and in the video presentations'

Each question chosen by the student elicits a different response from the 'virtual patient', appropriate to the question being asked. Each response from the patient presents the interviewer with the opportunity to change the direction of the interview or to ask further clarifying questions on the same subject. Individual interviewers, according to the type of questions they choose, create their own 'virtual interview' with the patient. A hypothetical example is as follows. In the beginning of the simulation, the patient says that she has been feeling depressed. The interviewer is presented with a choice of questions as follows 'For how long have you been feeling depressed?' and 'Tell me more about what it is like for you to be depressed'. Asking the first question, the interviewer fails to enquire about the true nature of the patient's experience and misses out on important information that is later required.

At the end of the interview, the interviewer is presented with the transcript of their interview that includes the type of questions asked and the clinical information elicited from those questions. They can then compare what they have elicited from the interview with the full range of clinical information that is available. They also have the opportunity to view a model interview with that patient and to view their own interview from beginning to end by streaming the responses together.

The student's ability to select the questions asked, places them in control of the 'virtual interview'. An online quiz allows students to conduct a 48-item mental state examination on the virtual patient just interviewed and receive instant feedback on their performance. Referring back to the hypothetical example above it can be seen that asking the first question, a closed question, leads to difficulties in completing the online mental state examination quiz. The first component of this exciting teaching tool, dealing with interviewing a patient with depression, is fully operational on our university intranet.

\section{Follow-up survey}

We have made this version of VISIOn available to medical students and have evaluated their experiences using the same questionnaire as described above. Students $(n=189)$ gave similar answers as to the previous survey except when asked if web resources had helped their learning of interview techniques. In the initial survey only $20 \%$ indicated that web resources were useful, but not surprisingly, in the follow-up survey $76 \%$ indicated that web resources had been useful.

In the follow-up survey, $65 \%$ said that they had used VISIOn more than once (>30 min) and $45 \%$ spent longer than an hour using VISIOn. Out of the participants, 55\% felt they were 'virtually interviewing' a patient, and all said they would be more inclined to use the internet as a result of their experiences with VISIOn.

We also conducted a focus group discussion with the students who had used the system. All agreed that further modules, simulating different disorders, would greatly benefit and contribute to their further development of successful interview skills.

\section{Conclusions}

Before the general introduction of this system, as part of our medical school curriculum, it is important to rigorously test the hypothesis that this will not just improve the student learning experience and use of online resources but also improve their psychiatric interview skills compared with their usual teaching. We are therefore embarking on a randomised controlled trial of the simulator using our medical students. Although we await the results of this ongoing trial, we are confident that this teaching tool is capable of enhancing the learning of clinical skills in an economical and time-efficient way, with the additional benefit of drawing students more effectively into the e-learning environment.

Medical schools are being encouraged to develop clinical skills laboratories where students can be taught skills and practice them in a safe, non-pressurised environment before they enter the hospital wards or community-based clinics. We have developed a simulator for teaching clinical interview skills in psychiatry that can easily be adapted to different disorders and to other teaching arenas. We have found it to be well accepted by our students. It is available to them at a time that suits, and with an internet connection, from a place that suits, and does not require additional teachers or patients. Future research and development should now focus on linking the interactive interview with expert advice by video link and with additional course materials.

\section{Declaration of interest}

None.

\section{Acknowledgements}

Funding and support for the VISIOn project has been generously provided by: Senior Lecturer's Office, Trinity College Dublin; Centre for Learning Technology, Trinity College Dublin; Centre for Academic Practice and Student Learning, Trinity College Dublin; AstraZeneca (Ireland) Ltd; Pfizer (Ireland) Ltd; and Janssen-Cilag (Ireland) Ltd. 
We have received funding 2005-2007 from the technology development phase of the commercialisation fund of Enterprise Ireland for a project called Adaptive

special articles Plug-in for Run-time Composition of Personalised eLearning and Adaptive Simulations (ADAPT).

\section{References}

ASSOCIATION OFAMERICAN MEDICAL BARROWS, H. (1993) An overview COLLEGES (1999) Medical School Objectives Project, Report III. Contemporary Issues in Medicine: Communication in Medicine. Association of American Medical Colleges. of the uses of standardized patients for teaching and evaluating clinical skills. Academic Medicine, 68, 443-451.

DEPARTMENT OF HEALTH AND CHILDREN (2003) Report of the
Inspector of Mental Hospitals.

Department of Health \& Children.

GENERAL MEDICAL COUNCIL (1993)

Tomorrow's Doctors. General Medical Council.

MAGUIRE, P., FAIRBURN, S. \&

FLETCHER, C. (1986) Consultation skills of young doctors - I - Benefits of feedback training in interviewing as students persist. BMJ, 293, 26.

Brian Fitzmaurice Seniori Clinical Lecturer, Department of Psychiatry, Trinity Centre for Health Sciences, Dublin, *Katie Armstrong Health Informatics Specialist, Department of Psychiatry, Trinity Centre for Health Sciences, St James Hospital, Dublin 8, Ireland, email: Katie.Armstrong@tcd.ie, Valerie Carroll Manager, Centre for Learning Technology, Trinity College Dublin, Declan Dagger Researcher/Programmer, Knowledge and Data Engineering Group, Trinity College Dublin, Michael Gill Professor, Department of Psychiatry, Trinity Centre for Health Sciences, St James' Hospital, Dublin

\section{ALAN KERR}

\section{In conversation withThomas Bewley}

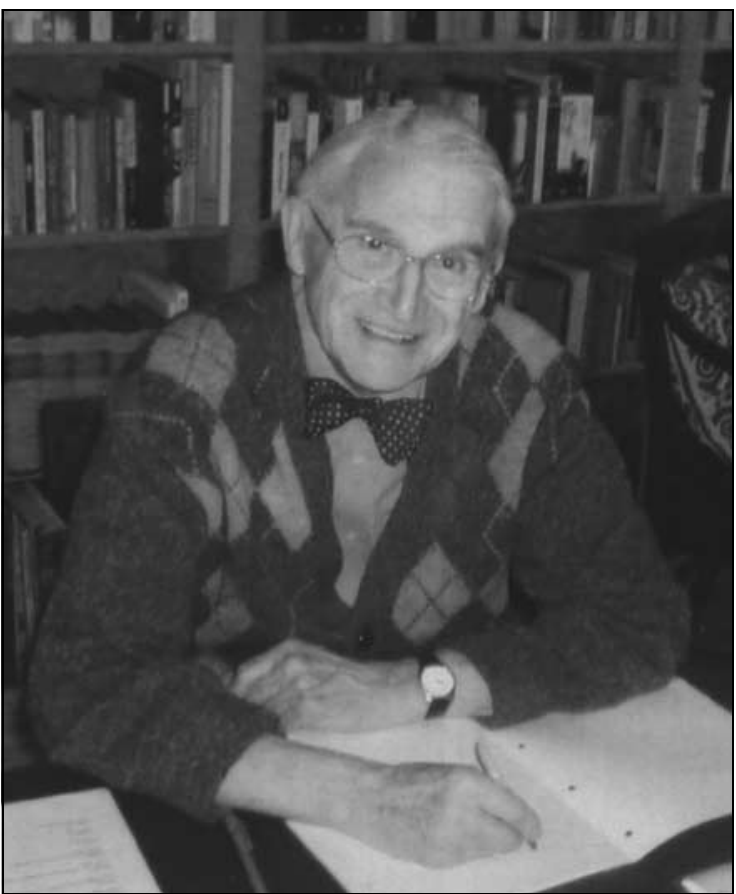

Thomas Bewley was interviewed by Alan Kerr at the Royal College of Psychiatrists on 10 March 2004.

You come from an Irish Quaker family, well known in Dublin in medical and café circles. Could you tell us a bit more about this background?

My great-grandfather was a Quaker. He was a millionaire entrepreneur but gave up one of his businesses when his partner wanted to sell alcohol. He then became a member of the Exclusive Brethren as he thought the Quakers weren't strict enough. He built an enormous
Thomas Bewley was much involved in the early years of the College. He was first Sub-Dean, second Dean and fifth President, and was a member of Council until 1996. When he left Council he was asked to write the official history of the College and its forerunners. He is a graduate of Trinity College Dublin and his psychiatric training was in Dublin, London and the USA. He became Consultant Psychiatrist to StThomas' Hospital and his professional career was much concerned with alcohol and drug dependence. His recommendations to the second Brain Committee led to the adoption of policies in effect today. He introduced the concept of 'harm reduction' as a pivotal principle in treatment. He was a founder of the Institute for the Study of Drug Dependence (now DrugScope) and a consultant adviser to the Department of Health and the World Health Organization for many years. He founded the College Research Unit and also started the Section (now a Faculty) of Substance Misuse. He was Screener for Health on the General Medical Council. His wife Dame Beulah Bewley is a distinguished epidemiologist.

meeting hall for them, and went bankrupt. This brought down Overend and Gurney, the largest Quaker finance house in that era. My grandfather, his only son, became a doctor and his first cousin set up the cafés. There were two streams of Bewley's in Dublin: the medical one was my grandfather, two of his sons, myself, my sister, two cousins and one of my daughters. The other branch is the café stream.

\section{What decided you on a career in medicine?}

My grandfather and my father looked after Bloomfield, a small Quaker mental hospital, which an earlier Bewley had helped to found on 'Retreat' lines. If I hadn't chosen medicine it would have been journalism, hoping to become a 'man of letters'. I thought psychiatry should be 